\title{
Reporting Outcomes of Extremely Preterm Births
}

Matthew A. Rysavy, MD, $\mathrm{PhD}^{1}$; Neil Marlow, $\mathrm{DM}^{2}$; Lex W. Doyle, MD, MSc ${ }^{3}$; Jon E. Tyson, $\mathrm{MD}, \mathrm{MPH}^{4}$; Frederik Serenius, MD, PhD ${ }^{5}$; Jay D. Iams, $\mathrm{MD}^{6}$; Barbara J. Stoll, MD ${ }^{4}$; Keith J. Barrington, $\mathrm{MB} \mathrm{ChB}^{7}$; Edward F. Bell, $\mathrm{MD}^{8}$

1. Department of Pediatrics, University of Wisconsin, Madison, WI, US

2. Elizabeth Garrett Anderson Institute for Women's Health, University College London, London, UK

3. Department of Obstetrics and Gynaecology, The Royal Women's Hospital, University of Melbourne, Victoria, Australia

4. Department of Pediatrics, University of Texas, Houston, TX, USA

5. Department of Women's and Children's Health, Uppsala University, Uppsala, Sweden

6. Department of Obstetrics and Gynecology, Ohio State University Wexner Medical Center, Columbus, OH, US

7. Department of Pediatrics, University of Montreal, Montreal, Quebec, Canada

8. Department of Pediatrics, University of Iowa, Iowa City, IA, US

Corresponding Author: Matthew A. Rysavy, MD, PhD, Department of Pediatrics, University of Wisconsin Hospital and Clinics, 600 Highland Ave, Madison, WI 53792 (mrysavy2@uwhealth.org)

Short Title: Reporting Outcomes of Extremely Preterm Births (max: 55 char)

Financial Disclosure: The authors have no financial relationships relevant to this article to disclose.

Funding Source: None

Potential Conflicts of Interest: The authors have no conflicts of interest relevant to this article to disclose.

Abbreviation:

$\mathrm{CI}$ - confidence interval

Version date: 5/9/2016

Word count: 2678 


\section{Contributors' Statement}

Dr. Rysavy drafted the initial manuscript and subsequent revisions and approved the final manuscript as submitted.

Drs. Marlow, Doyle, Tyson, Serenius, Iams, Stoll, Barrington and Bell contributed to discussions surrounding the drafting of the manuscript, reviewed and revised manuscript drafts, and approved the final manuscript as submitted. 


\begin{abstract}
Published reports of extremely preterm birth outcomes provide important information to families, clinicians, and others and are widely used to make clinical and policy decisions. Misreporting or misunderstanding of outcome reports may have significant consequences. This article presents seven recommendations to improve reporting of extremely preterm birth outcomes in both the primary and secondary literature. The recommendations should facilitate clarity in communication about extremely preterm birth outcomes and increase the value of existing and future work in this area.
\end{abstract}

\title{
Abstract word count: 79
}




\section{BACKGROUND}

Extremely preterm births constitute a small proportion of all worldwide births but a large portion of perinatal death and morbidity. ${ }^{1,2}$ They are a heterogeneous group with a wide range of potential outcomes - the probability of infant survival ranging from $0 \%$ to $>80 \%$ in the setting of modern intensive obstetric and neonatal care. ${ }^{3}$

Clinicians who care for families facing extremely preterm birth require accurate prognostic information to counsel families about what to expect and inform clinical decision making. However, prognostic data are important well beyond the period immediately preceding and following delivery. Survival following extremely preterm birth has improved in recent decades, ${ }^{4-}$ ${ }^{8}$ and clinicians of various specialties are now more likely than ever to care for survivors in all stages of their lives. ${ }^{9}$ Moreover, policy makers, administrators, researchers and others require information on extremely preterm birth outcomes in order to plan for the delivery of medical care, education, and other services and to improve how such services are provided.

For these reasons and others (Table 1), large studies of infant outcomes following extremely preterm birth have been performed around the world, often at great public expense..$^{10}$ To increase their value and to avoid waste, it is imperative that such studies are not only well conducted but are also accurately reported and in ways that encourage comparability across studies. ${ }^{11,12}$ The need for proper reporting applies to both primary research and secondary reports, such as popular media, reviews, and practice guidelines. 
In this article, we provide recommendations for reporting outcomes of extremely preterm births. This list of practices is not intended to be comprehensive but highlights several issues related to reporting that are commonly overlooked. ${ }^{13}$ We believe that following these few simple practices should reduce bias and increase the value of outcome data for families, clinicians, and society.

\section{RECOMMENDATIONS}

Good research starts with meaningful and important questions, and research reporting should reflect this. A well-composed question about extremely preterm birth outcomes should include a specific: a) patient population, b) set of "exposures" (i.e., factors that may affect the outcome),

and c) outcome (or set of outcomes). ${ }^{14}$ Our recommendations address each of these aspects separately.

\section{A. Population:}

Important considerations in extremely preterm birth outcome reporting include describing the study's source population and defining the study's inception point.

\section{Recommendation \#1: Describe the source population}

Birth outcomes should be reported with information on the setting in which the data were collected. Such information informs how data are interpreted and applied. Given changes in medical care over the past two decades, outcome data for extremely preterm births in 1995 may not wholly predict outcomes for births in 2016. Similarly, data from a low-resource setting may 
not be applicable to a well-resourced one. Reports of extremely preterm birth outcomes should include dates, geographic location, and any other information important to understanding the context of the study.

Studies of extremely preterm births generally report outcomes from single centers, multicenter networks, or geographically defined areas. Because hospital level of maternal and newborn care is associated with the likelihood of infant survival, ${ }^{15,16}$ geographically defined studies (i.e., those that include both community and referral hospitals as well as births outside of hospitals) are likely to produce outcomes that are different than outcomes from studies of single referral hospitals or networks of referral hospitals. The latter studies do not include infants who died prior to transfer to a higher level of care or that were healthy enough to avoid transfer altogether. A study's source population - whether single center, multicenter, or geographically defined should be clearly specified.

Of note, the appropriateness of a study's source population depends on the question asked or decision to be made with the data. To provide prognostic information to the family of an infant born in a hospital providing highly specialized maternal and newborn care (e.g., with a level 3 or 4 neonatal intensive care unit), ${ }^{17}$ statistics from that or similar units are preferred. However, for a policymaker concerned about resource allocation or a researcher interested in the effects of care regionalization, geographically defined studies provide the most appropriate information on these topics. Comparing birth outcomes from geographically defined studies (that include community hospitals and out-of-hospital births) to outcomes from tertiary care centers, without appropriate stratification, is uninformative and should be avoided. 


\section{Recommendation \#2: Define a study's inception point}

Related to a study's source population is its inception point. Studies of extremely preterm births vary in the point at which researchers begin to observe outcomes. Studies may collect data for all births (including intrapartum and antepartum stillbirths), ${ }^{5}$ all fetuses alive at presentation to the hospital $^{18}$ (or at the onset of labor ${ }^{19}$ ), all live births, ${ }^{7}$ or for only those infants who survive to admission to the neonatal intensive care unit. ${ }^{20}$

A study's inception point influences outcome statistics. ${ }^{21}$ Survival among infants admitted to the neonatal intensive care unit will be higher than survival for all liveborn infants, as the former excludes deaths that took place in the delivery room. Likewise, survival for live births will be higher than for fetuses alive at the onset of labor as the former excludes intrapartum stillbirths. ${ }^{22}$

As with a study's source population, the questions asked or decisions to be made should determine the appropriate inception point. For example, outcomes data intended for making decisions related to an impending extremely preterm birth should include the possibility of intrapartum stillbirth. Data used to answer questions about outcomes after admission to a neonatal intensive care unit should convey the relevant outcomes beginning at that point.

Studies should avoid reporting mixed inception points. For example, one study reported outcomes for all liveborn infants born at 22 or 23 weeks' gestation at 48 tertiary care hospitals (including those that died in the delivery room) together with outcomes for infants transferred to those hospitals from an outside hospital within 28 days following birth (therefore excluding infants who died prior to potential transfer or who survived without transfer) ${ }^{23}$ Statistics based 
on such a mixed group are difficult to meaningfully apply to any particular question or decision.

\section{B. Exposures}

Because of their significant impact on birth outcomes and on decisions made surrounding birth, we recommend that studies reporting extremely preterm birth outcomes take into account at least two factors: gestational age at birth and whether perinatal treatment was directed toward survival or palliation.

\section{Recommendation \#3: Stratify outcomes by gestational age at birth}

Although other factors affect the outcome of extremely preterm birth, the duration of fetal maturation is among the most important. ${ }^{24}$ Infants born at 20 weeks' gestation are too immature to survive while, in many places, the majority of infants born at 25 weeks' gestation survive. Moreover, many hospitals, ${ }^{25}$ professional societies, ${ }^{26}$ and countries ${ }^{27}$ have developed policies surrounding medical care based on gestational age.

Importantly, the margin of error for gestational age estimation may vary depending on its timing. ${ }^{28,29}$ Whenever possible, the best obstetric estimate (preferably based on first-trimester ultrasound) should be used to characterize infant gestational age.

Reports that lump together births across multiple gestational ages (e.g., 22-25 weeks) may obscure important information. For example, in the EXPRESS study, which included births from across Sweden from 2004 to 2007, the average rate of 1-year survival for 501 infants born alive 
at $22-25$ weeks' gestation was $64 \% .^{8}$ However, of the 51 infants born at 22 weeks $10 \%$ survived, and of the 205 born at 25 weeks, $81 \%$ survived. The average for infants born at 22-25 weeks conceals substantial differences in outcomes. When possible, primary reports of extremely preterm birth outcomes should stratify by gestational age week or smaller units. ${ }^{30}$

Of note, many factors beyond gestational age may affect extremely preterm birth outcomes. Due to the influence of factors such as infant birth weight, infant sex, antenatal corticosteroids, and plurality (i.e., being a twin, triplet, etc), the rate of survival for certain subgroups of infants born at 22 weeks' gestation is higher than the rate for other subgroups of infants born at 25 weeks' gestation. ${ }^{24,31}$ Small sample sizes limit the ability of many studies to report on subgroups beyond gestational age. However, when studies are large enough, authors may consider reporting outcomes across multiple variables including gestational age. Multivariable modeling provides one potential approach for taking into account several prognostic factors simultaneously. ${ }^{24,32}$

\section{Recommendation \#4: Report on decisions regarding treatment}

Decisions surrounding treatment for extremely preterm birth impact infant outcomes directly and should be accounted for in all reports. The willingness of an obstetrician to provide a cesarean section has been shown to correlate with whether delivery results in live birth or stillbirth, ${ }^{33}$ and large variations in rates of live birth and stillbirth have been shown among countries, ${ }^{34}$ withincountry regions, ${ }^{35}$ and even hospitals within the same city. ${ }^{36}$ Moreover, whether liveborn infants are resuscitated after birth influences survival statistics, and decisions to resuscitate may vary widely across countries ${ }^{37}$ and among tertiary care centers within the same country. ${ }^{38}$ 
Defining decisions about treatment presents logistic difficulties, but several approaches have been attempted. Bottoms et al collected data directly on obstetricians' and neonatologists' impressions of fetal viability. ${ }^{19}$ Serenius et al developed an ordinal scale to capture varying degrees of obstetric and neonatal care. ${ }^{39}$ Other studies have simply identified whether intensive care, as a binary (yes/no) variable, was provided after birth. ${ }^{5,24,38}$ The appropriate approach depends on the question to be answered with the data.

To include in reported statistics both birth outcomes following active treatment and birth outcomes that resulted from not initiating active treatment, without distinguishing between the two, results in significant bias. ${ }^{38,40,41}$ Outcome data for extremely preterm births where lifesustaining treatment was withheld (where palliation was the intended goal) should not be used to infer the probability of a good outcome for a birth where life-sustaining treatment is intended. Outcomes for births where active treatment is intended should be reported separately. ${ }^{42}$ This issue is particularly relevant for births at 22,23 , and 24 weeks of gestation, where the provision of active treatment is most variable. ${ }^{37,38}$

\section{Outcomes}

Study outcomes should be well-defined, relevant to study users, and reported with information regarding their accuracy and precision.

\section{Recommendation \#5: Describe outcome definitions}

Outcomes reported from extremely preterm birth studies should be meaningful to families, 
clinicians, and society. The most useful outcomes may be those that are developed a priori and in collaboration with families or other stakeholders who will use the data.

When reporting on composite outcomes such as "neurodevelopmental impairment" or "severe morbidity," both aggregate and component outcomes should be clearly defined. Both primary and secondary reports should avoid mixing or comparing outcomes of varying relevance to families, clinicians, and society. Where composite outcomes are necessary, such as with competing outcomes (i.e., where one outcome, such as mortality, precludes the possibility of other outcomes, such as developmental delay, blindness or deafness at 2 years' corrected age), primary reports should also present data for each component outcome.

Importantly, short-term morbidities should not be equated with long-term sequelae of prematurity in composite outcomes or when making comparisons among studies. Many infants who experience short-term morbidities have no resulting long-term health issues and vice versa. ${ }^{43,44}$ Special care should be taken when making comparisons among studies, as morbidities are often defined differently. Use of standardized definitions (such as those of the British Association of Perinatal Medicine) facilitates the comparison of outcomes across studies. ${ }^{45,46}$

Measurement of outcomes using developmental scores requires an appropriate reference group and studies differ in their selection of references. Standardized assessments such as the Bayley Scales of Infant and Toddler Development may be compared to historical normative reference data or to data from a concurrent term-born comparison group. The use of a term-born comparison group similar to the preterm population with term and preterm status blinded to the 
assessor may strengthen the relevance of developmental assessments and reduces the potential for expectation bias (i.e., where preconceptions about outcomes at early gestational ages influence the assessment). ${ }^{47,48}$

\section{Recommendation \#6: Describe the timing of outcome assessment}

The time at which an outcome is assessed (e.g., at 28 days after birth, at discharge, or at 5 years' corrected age) should be clearly reported as part of the outcome definition. Rates of both survival and morbidity vary depending upon the timing of outcome measurement. Developmental outcomes, in particular, vary over time, as some children may "catch up" with their peers whereas other deficits may only become apparent at later ages. ${ }^{49,50}$

An additional controversy related to the timing of outcomes concerns whether or not to correct age for the degree of prematurity. Outcomes may be reported by chronological age (i.e., the time since birth) or by "corrected age" (i.e., the time since the expected due date). ${ }^{51}$ A recent study demonstrated a persistent clinically important bias in cognitive test scores when age was not corrected for prematurity even into the teenage years. ${ }^{52}$

Primary reports should report the number of participants for whom data were not available at the time of assessment. They should report on differences between the participants with and without follow-up data available in order to convey whether the group with known outcomes is representative of the original cohort. ${ }^{53}$ 


\section{Recommendation \#7: Report the statistical uncertainty of the outcome}

Many studies of extremely preterm birth report outcomes such as survival or "neurodevelopmental impairment" as proportions. These outcomes represent the number of individuals with an outcome (the numerator) from a specified group (the denominator) - for example, 1169 of 2034 (57\%) infants born alive at $22-26$ weeks' gestation survived to 28 days. ${ }^{5}$ In some cases, outcomes are reported on a numeric scale (e.g., hemoglobin concentration of 12.6 g/dL or 1-minute Apgar score of 3) or as counts of recurring events (e.g., average number of emergency room visits per child during the first two years of life).

When reporting outcomes of extremely preterm births, which often involve small numbers, it is critical to convey the precision of the outcome estimate. Because larger sample sizes confer a more statistically precise estimate, reports should include information on both the number of infants included in the denominator of the statistic and a 95\% confidence interval of the estimate. For example, if $33 \%$ of infants born at 23 weeks' gestation survived, it is important to indicate whether 33\% (95\% CI: 16-56\%) of 18 infants survived, 33\% (95\% CI: $28-39 \%$ ) of 300 infants survived, or $33 \%$ (95\% CI: $31-36 \%$ ) of 1200 infants survived. Clearly, the last estimate is much more precise than the first; with only 18 infants, the $95 \%$ confidence interval includes rates both half and nearly twice as large as the point estimate of 33\%. Information on the precision of outcome estimates is critical to making informed decisions and to comparing outcomes between studies. 


\section{CONCLUSIONS}

Using a more standardized approach to report extremely preterm birth outcomes will facilitate clarity in communication about outcomes and increase the value of existing and future data.

Our recommendations (Table 2), which draw attention to issues related to outcome reporting for extremely preterm births, accord with existing and more general guidelines for reporting clinical outcomes. Guidelines for primary reports of observational studies (e.g., Strengthening the Reporting of Observational Studies in Epidemiology $[\mathrm{STROBE}]^{54}$ ) or for reviews ${ }^{55}$ and metaanalyses of prognosis statistics (e.g., those in development by the Cochrane Methods Prognosis Group $^{56}$ ) should be used where applicable to promote accurate and complete reporting.

Although issues surrounding the reporting of extremely preterm birth outcomes are in many ways unique, many of the practices listed above could be used to improve outcome reporting for other perinatal conditions, such as hypoxic-ischemic encephalopathy ${ }^{57}$ or congenital diaphragmatic hernia ${ }^{58}$, where similar issues of small sample size and wide variation in treatment occur.

Accurate information about extremely preterm birth outcomes is critical for making informed judgments about medical care. Such data can inform us about the success and failure of our efforts and guide our understanding of where further research is required. We owe it to patients and families, who participate in studies of extremely preterm birth outcomes, and to the public, who fund many such studies, to provide accurate, transparent reports of outcomes in the primary 
and secondary literature. Following the above-listed practices may help to increase the usefulness of outcome statistics for extremely preterm births, avoid bias and waste, and allow families, clinicians, and the public-at-large to make better informed decisions. 


\section{ACKNOWLEDGEMENTS}

We thank Drs. Prakesh Shah, Yumi Kono, and Reese Clark for their comments on a previous draft of this manuscript.

\section{REFERENCES}

1. Lau C, Ambalavanan N, Chakraborty H, Wingate MS, Carlo WA. Extremely low birth weight and infant mortality rates in the United States. Pediatrics. 2013;151:855-860.

2. Blencowe H, Cousens S, Oestergaard MZ, et al. National, regional, and worldwide estimates of preterm birth rates in the year 2010 with time trends since 1990 for selected countries: a systematic analysis and implications. Lancet. 2012;379:2162-72.

3. Patel RM. Short- and long-term outcomes for extremely preterm infants. Am J Perinatol. 2016;33:318-28.

4. Wilson-Costello D, Friedman H, Minich N, Fanaroff AA, Hack M. Improved survival rates with increased neurodevelopmental disability for extremely low birth weight infants in the 1990s. Pediatrics. 2005;115:997-1003.

5. Costeloe KL, Hennessy EM, Haider S, Stacey F, Marlow N, Draper ES. Short term outcomes after extreme preterm birth in England: comparison of two birth cohorts in 1995 and 2006 (the EPICure studies). BMJ. 2012;345:e7976.

6. Horbar JD, Carpenter JH, Badger GJ, et al. Mortality and neonatal morbidity among infants 501 to 1500 grams from 2000 to 2009. Pediatrics. 2012;129:1019-1026.

7. Stoll BJ, Hansen NI, Bell EF, et al. Trends in care practices, morbidity, and mortality of extremely preterm neonates, 1993-2012. JAMA. 2015;314:1039-1051.

8. Fellman V, Hellström-Westas L, Norman M, et al. One-year survival of extremely preterm infants after active perinatal care in Sweden. JAMA. 2009;301:2225-2233.

9. Doyle LW, Anderson PJ. Adult outcome of extremely preterm infants. Pediatrics. 2010; 126:342-351.

10. Marlow, N. Keeping up with outcomes for infants born at extremely low gestational ages. JAMA Pediatrics. 2015;169:207-208.

11. Chalmers I, Glasziou P. Avoidable waste in the production and reporting of research evidence. Lancet. 2009;374:86-89.

12. Glasziou P, Altman DG, Bossuyt P, et al. Reducing waste from incomplete or unusable reports of biomedical research. Lancet. 2014;383:267-276.

13. Guillén U, Weiss EM, Munson D, et al. Guidelines for the management of extremely preterm deliveries: a systematic review. Pediatrics. 2015;136:343-350.

14. Guyatt G, Meade MO, Agoritsas T, Richardson WS, Jaeschke R. What Is the Question? In: Guyatt G, Meade MO, Rennie D, Cook DJ, eds. Users' Guides to the Medical Literature: A Manual for Evidence-Based Clinical Practice. 3rd ed. New York, NY: McGraw-Hill; 2014.

15. Marlow N, Bennett C, Draper ES, Hennessy EM, Morgan AS, Costeloe KL. Perinatal outcomes for extremely preterm babies in relation to place of birth in England: the EPICure 2 study. Arch Dis Child Fetal Neonatal Ed. 2014;99:F181-188. 
16. Lasswell SM, Barfield WD, Rochat RW, Blackmon L. Perinatal regionalization for very lowbirth-weight and very preterm infants: a meta-analysis. JAMA. 304:992-1000.

17. Barfield WD, American Academy of Pediatrics Committee on Fetus and Newborn. Levels of neonatal care. Pediatrics. 2012;130:587-597.

18. Donohue PK, Boss RD, Shepard J, Graham E, Allen MC. Intervention at the border of viability: perspective over a decade. Arch Pediatr Adolesc Med. 2009;163:902-906.

19. Bottoms SF, Paul RH, Mercer BM, et al. Obstetric determinants of neonatal survival: Antenatal predictors of neonatal survival and morbidity in extremely low birth weight infants. Am J Obstet Gynecol. 1999;180:665-669.

20. Kyser KL, Morriss FH Jr, Bell EF, Klein JM, Dagle JM. Improving survival of extremely preterm infants born between 22 and 25 weeks of gestation. Obstet Gynecol. 2012;119:795800.

21. Hummler H. Benchmarking in neonatal intensive care: obstetrical and neonatal practices and registration policies may influence outcome data. Arch Dis Child Fetal Neonatal Ed. 2013 98:F96-F97.

22. Guillen U, DeMauro S, Ma L, et al. Survival rates in extremely low birthweight infants depend on the denominator: avoiding potential for bias by specifying denominators. Am J Obstet Gynecol. 2011;205:329.e1-7.

23. Ishii N, Kono Y, Yonemoto N, Kusuda S, Fujimura M. Outcomes of infants born at 22 and 23 weeks' gestation. Pediatrics. 2013;132:62-71.

24. Tyson JE, Parikh NA, Langer J, Green C, Higgins RD. Intensive care for extreme prematurity—moving beyond gestational age. N Engl J Med. 2008;358:1672-1681.

25. Kaempf JW, Tomlinson M, Arduza C, et al. Medical staff guidelines for periviability pregnancy counseling and medical treatment of extremely premature infants. Pediatrics. 2006;117:22-29.

26. Ecker JL, Kaimal A, Mercer BM, et al. American College of Obstetricians and Gynecologists and Society for Maternal-Fetal Medicine Obstetric care consensus: periviable birth. Obstet Gynecol. 2015;126:e82-94.

27. Fanaroff JM, Hascoët JM, Hansen TW, et al. The ethics and practice of neonatal resuscitation at the limits of viability: an international perspective. Acta Paediatr. 2014;103:701-708.

28. Spong CY. Defining "term" pregnancy: recommendations from the Defining "Term" Pregnancy Workgroup. JAMA. 2013; 309:2445-2446.

29. Method for estimating due date. Committee Opinion No. 611. American College of Obstetricians and Gynecologists. Obstet Gynecol. 2014;124:863-866.

30. Schindler T, Lui K, Bajuk B, Bolisetty S. In premature infants born at borderline viability, do days matter? J Paediatr Child Health. 2016;52:349-350.

31. Parikh NA, Arnold C, Langer J, Tyson JE. Evidence-based treatment decisions for extremely preterm newborns. Pediatrics. 2010;125;813-816. 
32. Medlock S, Ravelli ACJ, Tamminga P, Mol BWM, Abu-Hanna A. Prediction of Mortality in Very Premature Infants: A Systematic Review of Prediction Models. PLoS One. 211;6:e23441.

33. Bottoms SF, Paul RH, Iams JD, et al. Obstetric determinants of neonatal survival: Influence of willingness to perform cesarean delivery on survival of extremely low-birth-weight infants. Am J Obstet Gynecol. 1997;176:960-966.

34. Draper ES, Zeitler J, Fenton AC, et al. Investigating the variations in survival rates for very preterm infants in 10 European regions: the MOSAIC birth cohort. Arch Dis Child Fetal. Neonatal Ed. 2009;94:F158-F163.

35. Serenius F, Sjors G, Blennow M, et al. EXPRESS study shows significant regional differences in 1-year outcome of extremely preterm infants in Sweden. Acta Paediatr. 2014;103:27-37.

36. Gibson E, Culhane J, Saunders T, Webb D, Greenspan J. Effect of nonviable infants on the infant mortality rate in Philadelphia, 1992. Am J Public Health. 2000;90:1303-1306.

37. Gallagher K, Martin J, Keller M, Marlow N. European variation in decision-making and parental involvement during pre-term birth. Arch Dis Child Fetal Neonatal Ed. 2014;99:F245-F249.

38. Rysavy MA, Li L, Bell EF, et al. Between-hospital variation in treatment and outcomes in extremely preterm infants. $N$ Engl J Med. 2015;372:1801-1811.

39. Serenius F, Blennow M, Maršál K, Sjörs G, Källen K. Intensity of perinatal care for extremely preterm infants: outcomes at 2.5 years. Pediatrics. 2015;135:e1163-1172.

40. Verhagen AAE, Janvier A. The continuing importance of how neonates die. JAMA Pediatr. 2013;167:987-988.

41. Lantos JD, Meadow W. Variation in the treatment of infants born at the borderline of viability. Pediatrics. 2009;123:1588-1590.

42. Rysavy MA, Tyson JE. The problem and promise of prognosis research. JAMA Pediatr. 2016;170:411-412.

43. Schmidt B, Asztalos EV, Roberts RS, Robertson CMT, Sauve RS, Whitfield MF. Impact of Bronchopulmonary Dysplasia, Brain Injury, and Severe Retinopathy on the Outcome of Extremely Low-Birth-Weight Infants at 18 Months. JAMA. 2003;289:1124-1129.

44. Schmidt B, Roberts RS, Davis PG, et al. Prediction of Late Death or Disability at Age 5 Years Using a Count of 3 Neonatal Morbidities in Very Low Birth Weight Infants. J Pediatr. 2015; 167:982-986.

45. British Association of Perinatal Medicine. Classification of Health Status at 2 Years as a Perinatal Outcome-Report of a BAPM/ RCPCH Working Group. London, United Kingdom: BAPM; 2008.

46. Marlow N. Measuring neurodevelopmental outcome in neonatal trials: a continuing and increasing challenge. Arch Dis Child Fetal Neonatal Ed. 2013;98:F554-F558. 
47. Anderson PJ, De Luca CR, Hutchinson E, Roberts G, Doyle LW. Underestimation of developmental delay by the new Bayley-III Scale. Arch Pediatr Adolesc Med. 2010;164:352356.

48. Spencer-Smith MM, Spittle AJ, Lee KJ, Doyle LW, Anderson PJ. Bayley-III Cognitive and language scales in preterm children. Pediatrics. 2015;135:e1258-1265.

49. Ment LR, Vohr B, Allan W, et al. Change in cognitive function over time in very low-birthweight infants. JAMA. 2003;289:705-711.

50. Marlow N, Wolke D, Bracewell MA, Samara M. Neurologic and developmental disability at six years of age after extremely preterm birth. N Engl J Med. 2005;352:9-19.

51. Engle WA, American Academy of Pediatrics Committee on Fetus and Newborn. Age terminology during the perinatal period. Pediatrics. 2004;114;1362-1164.

52. Wilson-Ching M, Pascoe L, Doyle LW, Anderson PJ. Effects of correcting for prematurity on cognitive test scores in childhood. J Paediatr Child Health. 2014;50:182-188.

53. Wolke D, Sohne B, Ohrt B, Riegel K. Follow-up of preterm children: important to document dropouts. Lancet. 1995;345:447.

54. von Elm E, Altman DG, Egger M, et al. The Strengthening the Reporting of Observational Studies in Epidemiology (STROBE) statement: guidelines for reporting observational studies. BMJ. 2007;335:806-808.

55. Hayden JA, Côté P, Bombardier C. Evaluation of the quality of prognosis studies in systematic reviews. Ann Intern Med. 2006;144:427-437.

56. Cochrane Methods Prognosis Group. http://prognosismethods.cochrane.org/scope-our-work. Accessed February 1, 2016.

57. Wilkinson D. MRI and Withdrawal of life support from newborn infants with hypoxicischemic encephalopathy. Pediatrics. 2010;126:e451-e458.

58. Skari H, Bjornland K, Haugen G, Egeland T, Emblem R. Congenital diaphragmatic hernia: A meta-analysis of mortality factors. J Ped Surg. 2000;35:1187-1197. 


\section{TABLE 1. Uses of Extremely Preterm Birth Outcome Data}

Counseling and decision-making before and after birth

Preparing survivors and caregivers for what to expect across the life-course

Planning for services and allocating resources

Benchmarking hospital or regional outcomes

Identifying research questions and hypotheses

TABLE 2. Recommendations for Reporting Extremely Preterm Birth Outcomes

\begin{tabular}{|c|c|}
\hline Recommendation & Specific Example \\
\hline 1. Describe the source population & $\begin{array}{l}\text { Report the study dates and location. Define } \\
\text { whether geographically based, single center, or } \\
\text { multicenter. }\end{array}$ \\
\hline 2. Define the study's inception point & $\begin{array}{l}\text { Report statistics from a time point relevant to a } \\
\text { specific question or decision (e.g., for counseling } \\
\text { when presenting to the hospital in labor, include all } \\
\text { fetuses alive at presentation to the hospital). Avoid } \\
\text { combining multiple time points. }\end{array}$ \\
\hline $\begin{array}{l}\text { 3. Stratify outcomes by gestational } \\
\text { age }\end{array}$ & $\begin{array}{l}\text { Report outcomes by gestational age week. Larger } \\
\text { studies may include other relevant subgroups. }\end{array}$ \\
\hline $\begin{array}{l}\text { 4. Report on decisions regarding } \\
\text { treatment }\end{array}$ & $\begin{array}{l}\text { Report outcomes for births where active treatment } \\
\text { is intended separately from those where it was not. }\end{array}$ \\
\hline 5. Describe outcome definitions & $\begin{array}{l}\text { Describe the components of outcomes such as } \\
\text { "neurodevelopmental impairment" or "severe } \\
\text { morbidity." Avoid combining outcomes of varying } \\
\text { relevance. }\end{array}$ \\
\hline $\begin{array}{l}\text { 6. Describe the timing of the } \\
\text { outcome assessment }\end{array}$ & $\begin{array}{l}\text { Report the time at which outcomes were obtained } \\
\text { and the number of participants for whom outcomes } \\
\text { were available. }\end{array}$ \\
\hline $\begin{array}{l}\text { 7. Report the statistical uncertainty } \\
\text { of the outcome }\end{array}$ & $\begin{array}{l}\text { Include } 95 \% \text { CIs and denominator sizes (n's) for } \\
\text { statistics. }\end{array}$ \\
\hline
\end{tabular}

